NBER WORKING PAPER SERIES

\title{
THE IMPACT OF HEALTHCARE IT ON CLINICAL QUALITY, PRODUCTIVITY AND WORKERS
}

\author{
Ari Bronsoler \\ Joseph J. Doyle Jr. \\ John Van Reenen \\ Working Paper 29218 \\ http://www.nber.org/papers/w29218 \\ NATIONAL BUREAU OF ECONOMIC RESEARCH \\ 1050 Massachusetts Avenue \\ Cambridge, MA 02138 \\ September 2021
}

When citing this paper please use the following: Ari Bronsoler, Joseph Doyle and John Van Reenen. 2021. "The impact of Healthcare IT on clinical quality, productivity and workers" Annual Review of Economics 3: Submitted. DOI: https://doi.org/10.1146/annureveconomics-080921-101909. We would like to thank the MIT Workforce of the Future Economic Taskforce for financial support and comments on earlier drafts. We are grateful to David Autor, Leila Agha, Catherine Tucker, Cason Schmit, Tom Kochan and David Goldston for very useful comments and discussions. We also thank Rebecca Jackson and Jose Ignacio Velarde Morales for their invaluable research support. Van Reenen would like to thank the ESRC for financial support through the Programme On Innovation and Diffusion (POID). The views expressed herein are those of the authors and do not necessarily reflect the views of the National Bureau of Economic Research.

NBER working papers are circulated for discussion and comment purposes. They have not been peer-reviewed or been subject to the review by the NBER Board of Directors that accompanies official NBER publications.

(C) 2021 by Ari Bronsoler, Joseph J. Doyle Jr., and John Van Reenen. All rights reserved. Short sections of text, not to exceed two paragraphs, may be quoted without explicit permission provided that full credit, including $\odot$ notice, is given to the source. 
The Impact of Healthcare IT on Clinical Quality, Productivity and Workers

Ari Bronsoler, Joseph J. Doyle Jr., and John Van Reenen

NBER Working Paper No. 29218

September 2021

JEL No. I12,I18,J21,J24,O14

\section{ABSTRACT}

Adoption of health information and communication technologies ("HICT") has surged over the past two decades. We survey the medical and economic literature on HICT adoption and its impact on clinical outcomes, productivity and labor. We find that HICT improves clinical outcomes and lowers healthcare costs, but (i) the effects are modest so far, (ii) it takes time for these effects to materialize, and (iii) there is much variation in the impact. More evidence on the causal effects of HICT on productivity is needed to guide further adoption. There is little econometric work directly investigating the impact of HICT on labor, but what there is suggests no substantial negative effects on employment and earnings. Overall, while healthcare is "exceptional" in many ways, we are struck by the similarities to the wider findings on ICT and productivity stressing the importance of complementary factors (e.g. management and skills) in determining HICT impacts.

Ari Bronsoler

Massachusetts Institute of Technology

77 Massachusetts Ave

Cambridge, MA 02139

aribro@mit.edu

Joseph J. Doyle Jr.

MIT Sloan School of Management

100 Main Street, E62-516

Cambridge, MA 02142

and NBER

jjdoyle@mit.edu
John Van Reenen

Department of Economics

London School of Economics

Houghton Street

London, WC2A 2AE

United Kingdom

and NBER

j.vanreenen@1se.ac.uk

A spreadsheet of surveyed papers is available at https:/www.dropbox.com/scl/fi/84jdksabkqkad8n5990qg/ lit-review-for-paper-1.xlsx? $\mathrm{dl}=0 \& \mathrm{rlkey}=8 \mathrm{fbbv} 6 \mathrm{db} 91 \mathrm{vvd} 8 \mathrm{tmo} 13 \mathrm{sznbxe}$ 


\section{Introduction}

Healthcare delivery revolves around information gathering, inference, and communication across providers and with patients. As a result, it has long been recognized that health information and communication technology (HICT) holds enormous potential to improve productivity. In the US, it has now been about a decade since there was sharp rise in the adoption of HICT, especially the now-widespread use of Electronic health records (EHR). Recently, the pandemic further spurred growth in the use of innovations such as telehealth. This paper reviews the medical and economic literature addressing the drivers of HICT adoption and use and its effects on healthcare productivity, including clinical quality, healthcare costs, and the healthcare workforce. Our aim is to consider the state of knowledge on these questions and suggests paths forward to deepen our understanding.

The impacts of HICT could be enormous. Healthcare accounts for nearly one in every five dollars spent in the US and improvements in this sector have first-order effects on economic performance through sheer scale. Furthermore, like almost every other country, the proportion of national income absorbed by healthcare appears on an almost inexorable upwards trend. According to the National Health Expenditure Accounts, the fraction of GDP spent on healthcare has risen by about four percentage points every 20 years: from 5\% in 1960 to $9 \%$ in $1980,13 \%$ by 2000 , and then to nearly $18 \%$ in 2020 . This is driven by the aging population, costs of new technologies, and a natural tendency for humans to increase the fraction of their budgets on health as they grow richer (Anderson et al. 2003, Hall \& Jones 2007).

Apart from sheer scale, an advantage for tech applications is that healthcare is a knowledgeintensive industry characterized by fragmented sources of information (Atasoy et al. 2019). Therefore, in principle, it is perfect for the application of ICT. The enormous decline in the quality-adjusted price of ICT over the last 40 years should therefore be a great a boon to the sector (e.g., Bloom et al. 2012). ${ }^{1}$ In a well-known RAND study, Hillestad et al. (2005) estimated

Indeed, after the success of IBM Watson's Artificial Intelligence computer on the television quiz show Jeopardy, the first commercial application announced was in healthcare (see https://www.techrepublic.com/article/ibm-watson-the-inside-story-of-how-the-jeopardy-winningsupercomputer-was-born-and-what-it-wants-to-do-next/. 
that ICT adoption could save the US healthcare sector between $\$ 142$ billion and $\$ 371$ billion over a 15 -year period. ${ }^{2}$

Meanwhile, the US has long stood out from other Organization for Economic Co-operation and Development (OECD) countries in spending a much larger fraction of GDP on health, but achieving relatively disappointing results for this high expenditure (Papanicolas et al. 2018). For example, US life expectancy is lower in the United States than many European countries and indeed, appear to have stalled in recent years (Case and Deaton 2020).

In light of these trends, policymakers have stressed the use of HICT as a mechanism to improve efficiency and clinical outcomes. This culminated with the 2009 Health Information Technology for Economic and Clinical Health (HITECH) Act, which allocated around $\$ 30$ billion to increase adoption of HICT by subsidizing acquisition costs, changing reimbursement rules, and providing technical support. It emphasized the adoption of decision support capabilities and utilization at the point of care, formally referred to as "meaningful use." The rise in HICT installation across hospitals and doctors' offices has been impressive: although HICT has been used in healthcare since at least the early $1960 \mathrm{~s}$, fewer than $10 \%$ of hospitals (and fewer than $20 \%$ of physicians) were using EHRs prior to HITECH (Atasoy et al., 2019); by 2014, 97\% of reporting hospitals had certified EHR technology (Gold and McLaughlin, 2016).

Understanding the consequences of such a rapid expansion of technology services into the healthcare sector is more important than ever as the presence of HICT is evident in almost any part of the sector and the trends suggest this is just the beginning.

Despite the enormous potential and investment, the results of the impact of HICT have been disappointing (Sahni et al. 2017). A subsequent RAND study by Kellermann and Jones (2013) shows that the predicted savings had not materialized due, in part, to a lack of information sharing across providers and a lack of acceptance by the workforce in an environment where incentives run counter to the goal of reducing healthcare costs. Lessons from other industries suggest that the management of new technologies is an important driver of ICT productivity

See also Long (2018), on the broad applicability of IT from training to providing access and improving patient safety; Ippollitti (2017) and Harper (2012) on how data improves assignment of the health workforce and ramps up efficiency; and Gamache et al. (2018) on how big data better informs public policy. As a specific example, Rumbold et al. (2019) show how big data can dramatically improve service provision for diabetics. 
gains, and there are serious issues of management quality in the healthcare sector (e.g., Bloom et al. 2020).

It will take time for the sector to learn how to use the new tools provided by HICT, and it will be crucial to understand the effects of HICT and the innovations it makes possible on health and healthcare costs to guide future policy and practice. Jha et al. (2010) note that fewer than $2 \%$ of hospitals met the criteria of meaningful use prior to the HITECH Act, and the rise in HICT capabilities provides an opportunity to investigate the effects of such subsidies on healthcare productivity in general and the workforce in particular. This review aims to provide a foundation to capitalize on this opportunity.

We first describe the evolution of recent HICT, especially EHR in section II. We then turn to the impact of HICT on patient outcomes, productivity and costs in Section III. Section IV looks at the impact on the workforce, starting with new material on broad trends, before looking at the (smaller) literature. Section V compared our HICT results with the broader economy outside of health. Finally, Section VI offers some conclusions and areas for future research.

\section{The Recent Evolution of Health Information and Communication Technology II.1. New health information and communication technology}

In this section, we describe new forms of HICT that have the potential to drive substantial improvements in healthcare productivity. We begin by describing Electronic health records, which are the base for almost any IT application and then move on to highlight the most common applications of HICT. As mentioned above, the HICT sector is booming and several firms and startups are working on developing innovative ways in which to deliver healthcare, exploit medical information and automate parts of the process.

\section{II.1.1. Electronic Health Records}

The electronic health record, or EHR, is, at its core, a digitized medical chart. Deriving value from this technology requires a broad array of functions that gather, manage, and share digital health information. This information can then be exploited to support medical decision-making and operations. Ideally, information gathering begins before a patient encounter: retrieving records from other providers or past patient encounters. This, and other information, is then 
updated at the beginning of the patient's interaction with the physician or nursing staff; additional data — such as lab values, images, and progress notes — are added as the encounter progresses. This data can be made portable so that it may be shared with other providers or accessed via patient portals.

Figure 1 below shows how the adoption of Electronic health records has dramatically increased over the 2003-2017 period in the United States. The diffusion graph follows the traditional sigmoid pattern (e.g. Swan 1973), with an inflection point after the implementation of the HITECH Act. 


\section{Figure 1: Cumulative adoption of Electronic Health Records (EHR)}

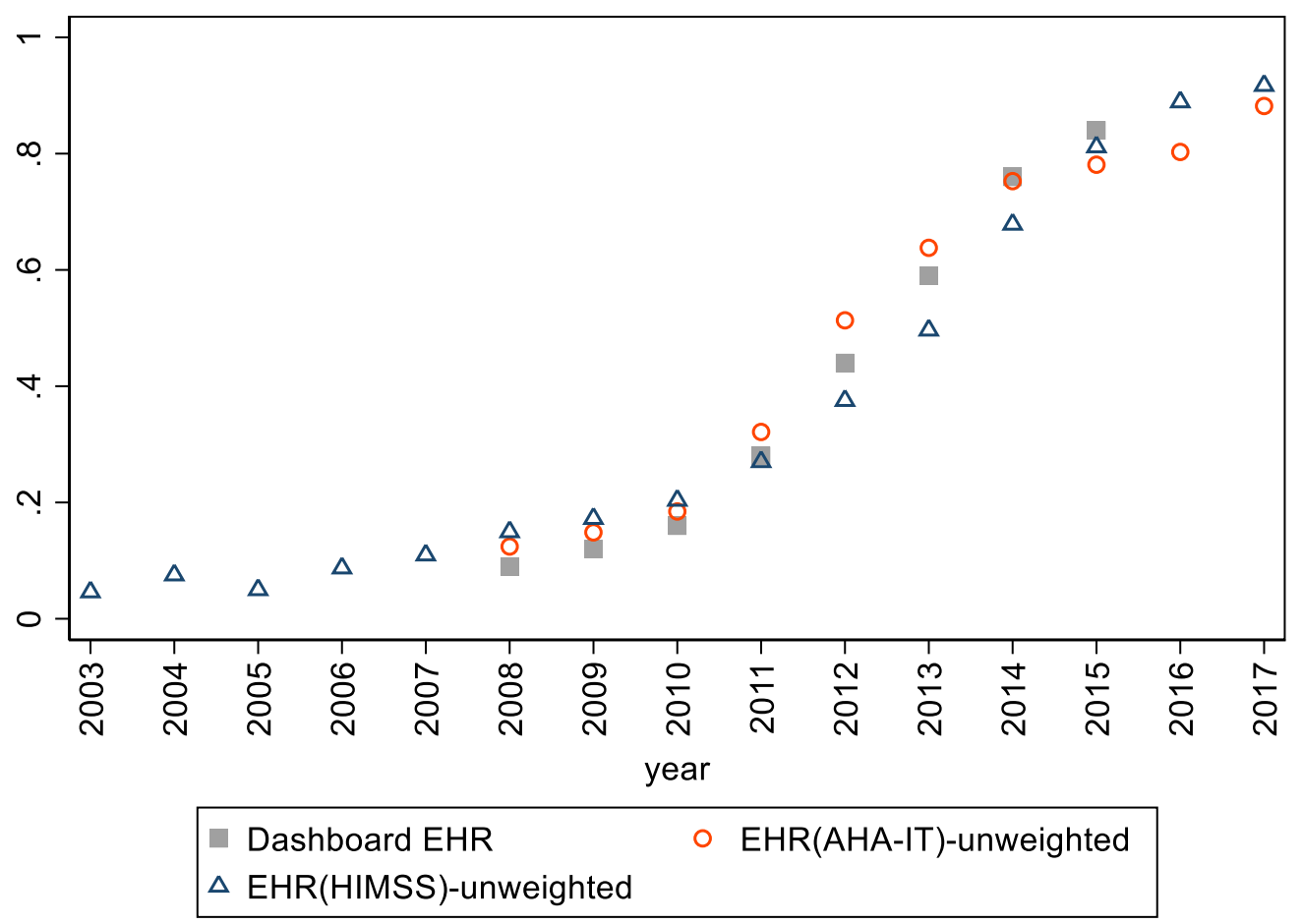

Notes: This figure presents estimates of the fraction of hospitals who were using "Basic EHR without clinician notes" in the year indicated in different databases. The Appendix describe these definitions in detail. The squares are official estimates from the Office of the National Coordinator $(O N C)$ of Health Information Technology (re-weighted to correct for nonrandom sample response). The circles are our own estimates from the AHA (American Hospital Associations) IT supplement and the triangles are our own estimates from HIMSS (Healthcare Information and Management Systems Society). The vertical axis is set so that $1=100 \%$ (complete adoption). Details of definitions are in the Appendix.

\section{II.1.2. Clinical Decision Support (CDS)}

Electronic health records may serve as a platform for decision support: established clinical guidelines or best medical practices may be operationalized within the EHR software using patient-level data to prompt providers with suggestions or raise flags regarding potentially risky interventions or inappropriate imaging (Doyle et al. 2019). These capabilities depend on detailed patient information and a provider interface at the point of care.

Clinical Decision Support can also support a broad range of functions, such as pre-specified order sets - a package of tests and subsequent procedures that can be chosen in an order-entry 
system with one click (e.g., common postoperative monitoring and care). These order sets, properly chosen by clinicians within health systems, may help implement evidence-based guidelines and best practice protocols by communicating to physicians the priorities of clinical leaders and by reducing the cost of adherence through ease of use. One marker for success is the reduction in unwanted, substantial variation in practice across clinics or physicians (Tsugawa et al. 2017). Ultimately, greater adherence to best practices could then provide further evidence of the effectiveness of the guidelines themselves. Another potential for CDS stems from algorithms can provide warnings, such as drug allergies or drug-to-drug interactions and dosage errors through automated dosage calculators. As with any warning system, attention to the acceptance of the warnings and concerns over "alert fatigue" will need to be managed (Ancker et al. 2017).

\section{II.1.3. New Communication Technologies}

Miscommunication is common in a complex system like modern medicine and McCullough et al. (2010) argue that it accounts for a substantial part of the estimated 44,000 annual US deaths due to inpatient hospital errors. For example, a prescription requires a physician, a pharmacist, and a nurse to coordinate. EHR can resolve this in principle-likely a substantial improvement from the days of illegible handwriting. Computerized physician order entry (CPOE) offers a more efficient way for physicians to communicate orders that may help prevent mistakes and help coordinate different players in the system.

In addition, telemedicine provides a new platform to deliver healthcare at a distance and has expanded enormously under the COVID pandemic due to the need for social distancing. ${ }^{3}$ Physicians can receive consultations from specialists (Long et al. 2018). It can aid health equity, as it is particularly attractive for patients in hard-to-reach communities who can be treated via a video connection. For example, Telestroke connects specialists to clinicians at the bedside of a stroke patient while transferring key clinical indicators in real time, which enables distant specialists to provide advice on treatment decisions (Akbik et al. 2017, Baratloo et al. 2018).

3 The CDC reports a 154\% increase in telehealth visits in March 2020 relative to March 2019 (https://www.cdc.gov/mmwr/volumes/69/wr/mm6943a3.htm). 


\section{II.1.4. Information Management and Healthcare Analytics}

With information moving from paper to digital records, HICT enables data to be more efficiently captured, stored, organized and analyzed which generates better diagnosis and treatment recommendations. This is particularly relevant for patients with multiple comorbidities and those who require intensive monitoring and testing. For example, Rumbold et al. (2020) consider diabetes, showing how machine-learning algorithms can capture blood sugar measurements daily and help predict with greater confidence who will develop a complication. This allows treatment such as medication choice and dosing to be personalized to each patient. Moreover, technology allows patients to carry their information on their cellphones, receive alerts and reminders of treatment, and track their health status. Such apps have the potential to improve treatment adherence.

A second example would be in public health (see Gamache et al. 2018). O'Donovan and Bersin (2015) showed how cellphones helped mitigate the Ebola outbreak. During COVID, an unprecedented effort on increasing surveillance capabilities has enabled many governments to very effectively use contact-tracing apps to identify potentially sick individuals (Altmann et al. 2020).

\section{II.1.5 Healthcare equity and algorithmic fairness}

HICT can affect equity in healthcare access and delivery for marginalized populations. On the one hand, digital health can significantly reduce access barriers as the digital transportation cost is close to zero and more experienced doctors can easily give advice to less educated practitioners remotely. On the other hand, the fact that telehealth requires higher quality technology and human capital can further deepen disparities in access. McCullough et al. (2021) use the coronavirus pandemic to understand the consequences of new technology on the "digital divide". In a Difference-In-Differences model, they compare telehealth utilization rates in 2019 and 2020 using data from a large commercial insurer. They show a (i) positive correlation between broadband penetration and the share of patients that shift to telehealth after the pandemic started; (ii) that individuals with more co-morbidities (and so a higher risk of dying from Covid), were less likely to shift to digital delivery; and (iii) that patients with an established 
relationship to a provider or with a higher income used digital visits more. This suggests an increase in health inequalities.

Relatedly, new technologies can improve equity by reducing inherent bias in treatment decisions, but they could also make things worse if the algorithms used produce biased estimates. There is some evidence of both. On the one hand, Ganju et al. (2020) exploit the staggered adoption of Clinical Decision Support Systems by hospitals and compare black and white patients' treatment before and after adoption. They show that the disparities in treatment of complicated diabetes were reduced after adoption as black patients were more likely to be revascularized (a procedure that allows them to keep their limb) instead of amputated. Moreover, they show that no harm is done because of this change as the delayed amputation rates remain the same. On the other hand, Obermeyer et al (2019) show that an algorithm that aims to identify the patients that would benefit the most from a program aimed at helping patients with complex medical needs is biased. They show that black patients that are identified as a very-high risk group of high utilization have on average $26 \%$ more chronic illnesses than their white counterparts. They further explain that the difference arises because of the decision to estimate risk of utilization through predicted costs; while the algorithm works well in terms of cost predictions, the fact that whites receive relatively more care, and thus spend more, induces the bias.

This discussion highlights the ambiguous effects of HICT on equity. Policy making must be context specific and not assume that it will always reduce the large existing inequities without intervention.

\section{II.2. Drivers of ICT adoption and meaningful use ${ }^{4}$}

The factors that affect the adoption of HITC are similar to those in the broader literature on technological diffusion (see the survey in Hall, 2005). Leading drivers include complexity, cost, competition, and complementary factors (such as human capital). For example, given the high fixed costs of adoption, it is no surprise that larger organizations are more likely to adopt IT. This section describes factors that are particularly relevant to healthcare.

\footnotetext{
${ }^{4}$ For more details see Gnanlet et al. (2019), which reviewed the literature covering 37 recent papers. We will discuss some of the broader issues affecting IT adoption, as well as healthcare-specific factors identified in the literature.
} 


\section{Patient Safety}

Although HITC offers the potential to improve patient safety substantially (Bates and Gawande, 2003), there is a risk that errors may be introduced (Harrington et al. 2011). The initial adjustment costs in most industries as firms learn how to use ITC are well documented (Brynjolfsson and Hitt 2000; Brynjolfsson et al. 2021), and this appears to be the case in healthcare as well. However, because patient safety may be affected by such a transition, there is a natural tendency toward greater risk aversion to all sorts of change in healthcare (Harrington et al. 2011, Raposo 2015).

\section{Patient Privacy}

A common concern that affects HICT adoption revolves around privacy. Congress passed a federal law, the Health Insurance Portability and Accountability Act (HIPAA), in 1996 with the expressed aim to aid in the sharing of health data by establishing national rules. There are concerns that organizations cite HIPAA in an effort to reduce sharing information with competitors (Adler-Milstein and Pfeifer 2017). States also passed privacy laws, and the sheer complexity of legal obligations is thought to reduce the benefits of data sharing and, thus, HICT adoption (Schmit et al. 2017, 2018).

Miller and Tucker $(2009,2011)$ investigated the role of state privacy laws following HIPAA, looking to see whether HITC systems are less attractive when there are additional state privacy laws. The authors argue that the gain to a network from adopting EHR is that systems can interoperate within the network across disparate hospitals and other providers. However, these interoperability benefits are undermined when privacy laws are restrictive, so hospitals have less incentive to adopt. Their main evidence in support of this relationship between privacy and adoption is that every additional hospital that adopts EHR within a health service area increases the likelihood of adoption of a neighboring hospital by $7 \%$, but the effect is weakened when states have more stringent privacy protections.

In particular, Miller and Tucker find that hospitals in states that toughened privacy laws (11 states introduced these enhancements over the 12-year period they studied) reduced IT adoption by about $24 \%$. Similar findings are found when they instrument for privacy-law changes using 
variation in the political mix of the states' legislatures. Another set of instruments included measures of the value of privacy in the state, such as the proportion of the state that joined a "do not call" list that prevents telemarketers from calling people's homes, and the state's openness to immigration-verification systems when obtaining drivers licenses. These checks bolster the claim that privacy attitudes and laws are drivers of HITC adoption.

\section{Fragmentation}

Coordination is hampered because of the different systems run by competing healthcare firms: from different providers, including physician groups that are not employed by hospitals, to different insurers, there is a wide array of players whose systems are not integrated (Cebul et al. 2008; Agha et al. 2020). In contrast, the government-run Veterans Administration's nationwide HICT infrastructure is often lauded for its interoperability across units (Chan et al. 2020).

Fragmentation is one reason for the slow adoption of HICT, but it is part of broader reasons that are not unique to the US. One example is the United Kingdom's National Health Service, which spent $\$ 16$ billion on a failed attempt at EHR in the mid-2000s. The fact that this happened in a system without fee for service and a fully integrated insurer suggests more deep-rooted problems than the idiosyncrasies of the US healthcare system..$^{5}$

\section{Resistance to Change and Management}

In this environment with concerns over patients safety and privacy among fragmented providers, many stakeholders can resist change, especially when there is asymmetric information between the IT decision-makers (senior managers) and those who are using the tools (medical staff). Physicians have been found to play a particularly important role because without their buy-in, it is very hard to effectively diffuse IT (Cohn 2009). Compared to other industries, healthcare providers are powerful, high-human-capital workers who know much more about the delivery of

See the UK government's 2011 review of the National Programme for IT in the NHS (https://publications.parliament.uk/pa/cm201012/cmselect/cmpubacc/1070/107003.htm) that was launched in 2002. Interestingly, Wachter (2017) describes that Clive Granger, the head of the UK program, was influential in getting George W. Bush interested in a similar U.S. initiative as the precursor of the HITECH Act. 
care than senior managers. Hardiker et al. (2019), for example, found that if nurses did not find the IT helpful, they swiftly found workarounds and did not use the technology.

Employee engagement is a key part of the management practices emphasized by Bloom and Van Reenen (2007), and healthcare provider "buy in" has been found to be important for the successful adoption of HICT (Bohmer and Ferlins 2008). ${ }^{6}$ It appears that in healthcare, negotiation and cooperation is an important driver of acceptance that is necessary to effect change. Litwin (2011) describes engagement and cooperation with the workforce at Kaiser Permanente, which preserved employment (e.g., Kaiser Permanente had to provide alternative jobs for the chart room) while improving patient satisfaction. Training also seems critical. Aron et al. (2011) performed a systematic study of multiple units in hospitals to identify factors that influence automation and help reduce medical error rates. They found that training of hospital staff in quality management and automation of control systems improves outcomes and reduces errors due to subjective decision-making. Mantzana et al. (2007) argue that management is critical in identifying who requires training and in determining the roles and responsibilities of the different healthcare employees when adopting and integrating HICT systems.

\section{Competition}

The EHR market features three dominant firms that cover over $65 \%$ of the market: Epic, Meditech and Cerner. ${ }^{7}$ Many have argued that this lack of robust competition raises prices and thereby slows adoption. Further, dominant EHR suppliers have incentives to make their systems hard to mix with others since this enables them to increase switching costs and reduce competition. This strategy of raising rival costs through limiting interoperability is known as “information blocking" and reduces the benefits of adoption because of reduced connectivity. ${ }^{8}$

\footnotetext{
${ }^{6}$ Bohmer and Ferlins (2008) describes practices at Virginia Mason in Seattle, such as the "Tuesday Stand Up" where all staff meet to discuss data on performance tracking and targets. This helps with engagement and understanding of how well the hospital is managing with productivity, quality, and implementation of new technologies. See Bloom et al (2020) for econometric evidence on the importance of management in hospitals. ${ }^{7}$ Data from the Office of the National Coordinator for Health Information Technology, 2015.

${ }^{8}$ Limiting interoperability to strengthen a dominant position is used in many other digit industries. For software examples, see Kuhn and Van Reenen (2009).
} 
The 2016 " $21^{\text {st }}$ Century Cures Act" sets interoperability requirements for all EHR vendors to attempt to limit this practice.

On the hospital provider side, competition is often weak (Cooper et al. 2019). As a result, incentives to improve efficiency through the adoption of technology and other best practices may blunted (e.g., Bloom et al. 2015). Cutler (2011) point out that healthcare is exceptionally inefficient in generating incentives for innovation. Despite recent payment reforms, most providers continue to operate on a basis where greater provision of care results in greater profits ("fee for service"), which means that there is little incentive to seek lower costs through HICT adoption and use.

Overall, the effects of competition are theoretically ambiguous. Greater competition could provide incentives to invest in HICT to improve quality and attract more patients (Chandra et al. 2016). At the same time, competition may provide incentives to avoid seamless information exchange to increase patient switching costs.

\section{Summary}

There are many reasons why adoption of HITC may be inefficient. Resistance on the part of the workforce appears particularly relevant in healthcare due to the high adjustment cost and potential risks to patients in an environment with privacy concerns. The competitive landscape for HICT suppliers and among providers who constitute demand for HICT provide their own hurdles. Greater understanding of the relative importance of these factors would be useful in understanding the market for HITC and suggesting useful variation to study its effects.

\section{Effects of HICT on Productivity III.1 Methodology}

For our literature review, we focused on reviews from the medical literature and on economics papers related to the effect of health ICT adoption. More details can be found in the Appendix. In brief, we reviewed 975 papers and we summarized 65 in detail. -The increase in published papers on HICT over time has been remarkable. There were 118 publications with "Health Information Technology" in the title or abstract of the paper in 1990 and 3,556 in 2018. Moreover, the flow for papers with "Electronic Health Records" in the title or abstract grew from three in 1990 to 
3,989 in 2018. The growth after the HITECH Act was passed is particularly impressive, with the number in the year before the Act in 2008 at only 568.

\section{III.2. Impact of Health ICT on health outcomes}

\section{Medical Literature}

There is a large medical literature focusing on the impact of HICT on patient outcomes, and we focus on four reviews covering a total of 637 unique papers between 1995 and 2017. The most recent was Kruse and Beane (2018) covering papers published between 2011 and 2017; the next was Buntin et al. (2011) covering 154 papers 2007-2010; then Goldzweig et al. (2009) reviewed 179 papers 2004-2007 and the earliest was Chaudhry et al. (2006) examining 257 studies 19952004.

The typical study is cross sectional across units (e.g. hospitals or physician offices) or within healthcare providers (across departments or healthcare staff) relating the use of a particular form of HICT to a particular patient outcome. More rarely, longitudinal data allow time series or difference-in-differences designs with great attention to measurement.

Our summary reading of the medical literature is that:

1. Overall, there is an average positive effect of HICT on patient outcomes and healthcare productivity.

2. There is much heterogeneity between individual studies in magnitudes (and to a lesser extent, signs). There are a non-trivial fraction of inconclusive studies and some even finding negative effects.

3. Later papers and reviews have tended to find more positive effects than earlier ones.

The most recent review, Kruse and Beane (2018), studied 37 papers and found significantly positive effects of HICT in 30, insignificant effects in seven and no negative results. The survey immediately before (Buntin et al, 2011) found positive and significant effects in $60 \%$ of papers, $30 \%$ were insignificant and only were $10 \%$ significantly negative. Although the average study was positive at the mean in Chaudhry et al. (2006), the earliest review, it was the most mixed. 
The tendency to find larger benefits of HICT in more recent studies may reflect a learning curve both at the hospital level and system-wide. At the healthcare provider level, it can take many years before a hospital learns how to use HICT effectively due to adjustment costs, which generates a long and variable lag between adoption and outcomes. Later studies usually have longer data series to track such changes. Learning also operates between hospitals, as systems learn from the EHR mistakes of others. Since later studies are on later years, they are further along this economy-wide learning curve.

Indeed, the current state of HICT subsidies in the US provides incentives for the use of the technology through the sharing of information within and across providers. Menachemi et al. (2018) reviewed 24 articles to assess the effect of such "health information exchange". Health information exchange systems are known to vary widely in their levels of success, and this review found that they tend to reduce costs by reducing duplicate procedures and imaging.

\section{Economics Literature}

Work in the economics literature pays more attention to potentially exogenous sources of variation in the use of HICT. Taken as a whole, this literature tends to find less positive effects compared to the medical literature.

McCullough has a series of papers carefully examining the impact of HICT on healthcare quality. Overall, the findings suggest that it improves patient safety, increases guideline adherence, and reduces the likelihood of death.

McCullough et al. (2016) consider a large range of technologies using IT adoption surveys from HIMSS and Medicare claims data from 1998-2007. They focus on four common diagnoses (acute myocardial infarction, congestive heart failure, coronary atherosclerosis, and pneumonia). In a difference-in-difference analysis studying the staggered adoption of HICT across hospitals, they find beneficial effects of adoption along a key dimension: illness severity. For pneumonia and heart failure patients, the benefits are visible for the top 3-4 deciles of illness severity. For other heart conditions, such as heart attacks, the results are more mixed. Across the technologies studied, they attribute the benefits to improved information management and coordination across providers as opposed to clinical decision support. 
Parente and McCullough (2009) examine three technologies: EHR, picture archiving and communication systems (PACs), and nurse charts. Using a similar difference-in-differences strategy, they find that only EHR has a clear, statistically significant (but small) effect on improving patient safety. Similarly, McCullough et al. (2010) combine data from the American Hospital Association's (AHA) annual survey that captures hospital characteristics, the Health Information and Management Systems Society (HIMSS) that captures HICT adoption, and data from the Centers for Medicare and Medicaid Hospital Compare database that captures hospital quality measurements. They conclude that EHR and computerized physician order entry (CPOE) have a small positive effect on only one of the six quality measures they studied: the proportion of correct medications provided. Moreover, they find that the effect is larger for teaching hospitals. These two papers rely on relatively short panels (4 years), however, which limits the ability to test whether hospitals that adopt HICT are on different trajectories compared to those that do not.

Using Medicare claims data from 1998-2005, Agha (2014) uses event studies and fixed effects regression models that control for hospital and state-year fixed effects (so essentially the same as difference-in-differences), along with separate linear trends for eventual adopters and hospital characteristics, including hospital size, technological investment, and patient characteristics. Like McCullough et al. (2016), she finds no effect on patient mortality or readmission on average. 9

By contrast, Lin et al. (2018) studied Medicare claims from 2008-2013, used the 30-day mortality rate by year for 15 common conditions on each hospital as a dependent variable and found, with a similar flexible strategy, that adopting additional EHR features reduced mortality, but only after a number of years. This suggests that HICT applications may be improving and that there may be important learning effects: in the short run, there are little/no effects, but after several years (presumably when learning has happened) the effects do show some positive results. (2016) find. She also finds increases in costs over five years, like Hitt and Tambe (2016). 
McKenna et al. (2018) find reductions in mortality after the introduction of HICT in New York State. They use a difference in difference approach, but look specifically before and after the HITECH Act, which plausibly increased incentives to adopt IT. However, the assumption that all of the differential adoption across hospitals before and after 2011 is solely due to HITECH incentives, is a strong one.

All the papers discussed in this subsection so far use difference-in-difference analysis approaches looking at the change of performance following the change in HICT adoption across hospitals. This controls for permanent unobserved heterogeneity through the hospital fixed effects, which is an advantage over cross sectional studies. If adoption rates respond to shocks that affect hospital performance that are not controlled for by other hospital-specific variables and time effects, however, the coefficient on HICT will still be biased.

Miller and Tucker (2011) employed a particularly novel set of empirical strategies to estimate causal effects of HITC. They focus on all births in U.S. hospitals from 1995-2006 and identify technology adoption using HIMSS 2007. 38\% of their 3,764 hospitals have EHR by the end of the period in 2006 . Their main approach uses county fixed effects and finds that a $10 \%$ increase in the adoption of EHR results in a substantial 3\% reduction in neonatal deaths following HITC adoption. To address endogeneity concerns, they show that results are robust when they use changes in privacy laws to generate plausibly exogenous variation in adoption, as noted above. The instrumental-variable estimates grow in magnitude, although are less precise.

Chan et al. (2020) use an identification strategy that exploits plausibly exogenous variation in ambulance-company assignment during an emergency health condition. Similar to Doyle et al. (2015), they find that this assignment affects hospital choice in a quasi-exogenous way, which provides a way to compare similar patients who happen to be treated in different hospitals. They find that for marginal patients transported to Veterans Administration (VA) hospitals have a substantial survival benefits compared to non-VA hospitals. One potential explanation is that VA hospitals are known to have more advanced HICT. To investigate this mechanism, they restrict the sample to patients treated at non-VA hospitals and find that patients who were transported to their usual hospital (a hospital where they have been treated in the past) have a substantially larger survival benefit compared to being treated in a new environment; 
importantly, this effect is only apparent during the time period after the HITECH Act, when presumably HICT has been widely adopted by hospitals. The authors acknowledge that this is suggestive evidence of the effects of HICT on health outcomes, with results that imply substantial gains of HICT for emergency patients.

\section{Summary on studies of the impact of HICT on health outcomes}

Overall, the economics literature, as its medical counterpart suggests improvements in healthcare quality following HICT adoption, albeit more modest with plenty of heterogeneity across studies. Again, these effects are not manifest immediately but take time, likely due to the learning that needs to take place. Finally, the results differ across patient groups, with evidence suggesting that more complex patients (with greater comorbidities) see greater benefits of the new technologies.

\section{III.3. Impact of Health ICT on productivity}

In addition to patient health outcomes, the economics literature typically reports results on productivity, usually measured as value added defined as revenue minus intermediate inputs (supplies, linens, clothing, etc.). Lee, McCullough, and Town (2013) estimate a production function using data on 309 hospitals in California combined with HIMSS data over the period 1998-2007. To estimate effects of HICT adoption on value added, they use proxy-based methods (e.g., Olley and Pakes 1996; and Ackerberg et al. 2015), as well as dynamic panel data models (e.g., Arellano and Bond 1991). They find very high returns to IT (both labor and capital), which suggests that there may be barriers to investment (hence the high marginal returns).

Hitt and Tambe (2016) examine the impact of EHR in 304 New York State nursing homes. Using a difference-in-differences approach that relies on variation in implementation dates, similar to the ones described above, they study efficiency (distance from the production possibility frontier given their inputs) and productivity (improvements in value). They find 1\% higher productivity and 3\% greater efficiency following EHR system implementation. A limitation of the analysis is that nursing homes that adopt HICT may be on a different productivity trajectory compared to those that do not. One of the most interesting findings is that that facilities that are one standard deviation higher on a work-organization scale - composed of 
practices that encourage employee collaboration, decision-making, suggestions, and problemsolving - are associated with a productivity increase of $1.5 \%$ or more when HICT is adopted. This is consistent with many of the studies from other industries suggesting an important role for complementary investments to IT, such as managerial skills (e.g., MacDuffie 1995; Bresnahan et al. 2002; or Bloom et al. 2012).

\section{III.4. Impact of HICT on healthcare costs}

Healthcare costs are typically measured in two ways: healthcare expenses paid by payers such as insurance companies and government programs such as Medicare and Medicaid, or input costs incurred by providers including labor and capital expenses. The former is also the revenue received by healthcare providers, and a concern is that HITC has enabled providers to bill payers more effectively. HITC can change the ability to code diagnoses and procedures in ways that increase bills for tasks that previously went uncompensated or undercompensated. In hospital billing, insurers pay based on the complexity of diagnoses, number of patient history and facts (like cough, belly pain, and patient history), and organs examined. EHR can maximize the billing taking into account this billing structure. This clearly creates more profits for providers and might be a more accurate and systematic recording than before the HITC was introduced. However, if the main effect were to "upcode" patients' health, HITC would inflate healthcare spending. In addition, HITC may be a complement to other new technologies, such as personalized medicine or diagnostics for novel devices or treatments that have higher marginal costs compared to legacy technologies.

\section{Healthcare Expenses Paid by Providers}

Many of the papers already discussed (particularly those in the economics literature) look at costs as well as quality. Agha (2014), described above, found an increase in billing following HICT adoption. She finds that medical expenditures over the year following a hospitalization are flat until HICT adoption when they grow over the following four years, eventually reaching $4 \%$ higher. No effect is found for labor demand, however. Combined with little effect on health outcomes, these results are consistent with concerns that modern HITC could be a means to improve the efficiency of billing rather than treating patients. 
Related, Ganju et al. (2021) analyze through a flexible fixed effects model whether the introduction of CPOE leads to upcoding. They use data from the Healthcare Cost and Utilization Project State Inpatient Database between 2004-2013 for four US states (Florida, Arizona, Maryland and Kentucky) and create severity indexes based on complication and comorbidity codes. They find that there is an increase in the severity index of patients after the introduction of CPOE but only in hospitals that are not subject to Medicare's Recovery Audit Program, which aims to reduce inflated billing. ${ }^{10}$ Understanding whether the adoption of new technology leads to an increase in severity coding, and whether that effect is because of improved accuracy in diagnosis or upcoding, remains an interesting area of research.

\section{Operating Costs}

While comparing similar hospitals that adopt at different times can yield causal estimates of the effects of IT, the usual identification concern remains that hospitals may adopt depending on changing market conditions that can also affect healthcare productivity. Dranove et al. (2014) offer a number of empirical strategies with the aim of overcoming such spurious correlations. In addition to considering the different timing of IT adoption across providers, the authors have three empirical strategies to focus on variation in adoption that can yield plausibly causal estimates. These designs are: (a) focusing on hospital systems and adoption of IT by hospitals within the system in other markets (similar to Miller and Tucker 2009, 2011); (b) focusing on adoption by competitors to hospitals within the same system; and (c) using the fact that hospitals based farther from major EHR vendors (like Epic) are slower to adopt. These sources of variation in HICT adoption yield less precise estimates, but they all tell a similar story; namely that there were large increases in costs immediately after EHR adoption. The authors stress that over time these costs start to decline, which suggests some positive learning effects on productivity.

\section{Summary on healthcare costs}

As discussed above, the potential for HITC to lower healthcare spending is immense (Hillestad et al. 2005). The literature yields evidence on healthcare spending that is more mixed compared

\footnotetext{
${ }^{10}$ Adler-Milstein and Jha (2014) employed difference-in-differences strategy and did not find a significant effect on either severity or spending from adopters when compared to controls. With 4 years of data, it is difficult to check whether adopters were on a different trajectory compared to control hospitals, however.
} 
to the literature that considers clinical outcomes. Overall, HICT adoption tends to be associated with an increase in costs, at least in the initial years, and the barriers for successful adoption described in Section II provide some guidance on the frictions that can impede progress. However, certain applications like health information exchange could lead to a reduction in costs. Given the variation in effects found over time, findings for more recent time periods and for specific applications would be valuable evidence on longer-run effects.

\section{Impact of HICT on the Healthcare workforce}

There is considerable concern that technology will displace workers, which depends on whether the new tools are net complements or substitutes with labor and there is still much to learn about how technology interacts with heterogeneous workers (Acemoglu and Autor 2011). The healthcare sector is both very large and heterogeneous in terms of skills and tasks. As we build toward understanding the effects of HICT on healthcare productivity, examining the labor market implications is a priority that to date has been understudied. This section provides background on the healthcare workforce and reviews the sparse literature on the topic.

\section{IV.1 Background Facts on the healthcare workforce}

The growth in US healthcare spending is accompanied by growth in healthcare employment. Figure 2 shows growth in the workforce since 1990. 11 Healthcare workers are those employed in three main sectors: hospitals, ambulatory healthcare facilities (e.g., physicians' offices and dentists), and nursing/residential care facilities. $\frac{12}{2}$ The number of healthcare workers has doubled from about eight to 16 million, rising from just over $7 \%$ to almost $11 \%$ of all workers. In addition, healthcare jobs appear to be largely recession proof, rising year after year despite the total number of workers falling during the recessions of the early 1990s, early 2000s, and 2008-

11 U.S. Bureau of Labor Statistics, All Employees, Health Care [CES6562000101], retrieved from FRED, Federal Reserve Bank of St. Louis; https://fred.stlouisfed.org/series/CES6562000101, July 16, 2020. U.S. Bureau of Labor Statistics, All Employees, Total Nonfarm [PAYEMS], retrieved from FRED, Federal Reserve Bank of St. Louis; https://fred.stlouisfed.org/series/PAYEMS, July 16, 2020.

12 These are defined based on industry codes: NAICS 621, 622, and 623. Of course, many of the workers here are not healthcare occupations (e.g., there are janitors, cooks, security guards, general managers, etc.). In addition, some healthcare occupations will be outside these sectors (a nurse employed by a school or corporation, for example). However, the vast bulk of health occupations are in these industries. For example, only $5 \%$ of physicians and $10 \%$ of nurses work outside our three healthcare sectors. In addition, the trends are broadly similar on other definitions of the healthcare workforce. 
09. The only time there has been a big fall is during the COVID-19 pandemic of 2020, but even this fall in healthcare jobs has been much lower than the workforce in general. The resilience of the healthcare workforce is not surprising, as the demand for healthcare rises steadily, even in bad economic times. Finally, there is not much discernible impact of the 2009 HITECH Act in Figure 2. To the extent that the Act, or HICT more broadly, did influence employment, it is not easily detectable in the headline numbers.

\section{Figure 2: Healthcare Workers and Total Workforce (thousands)}

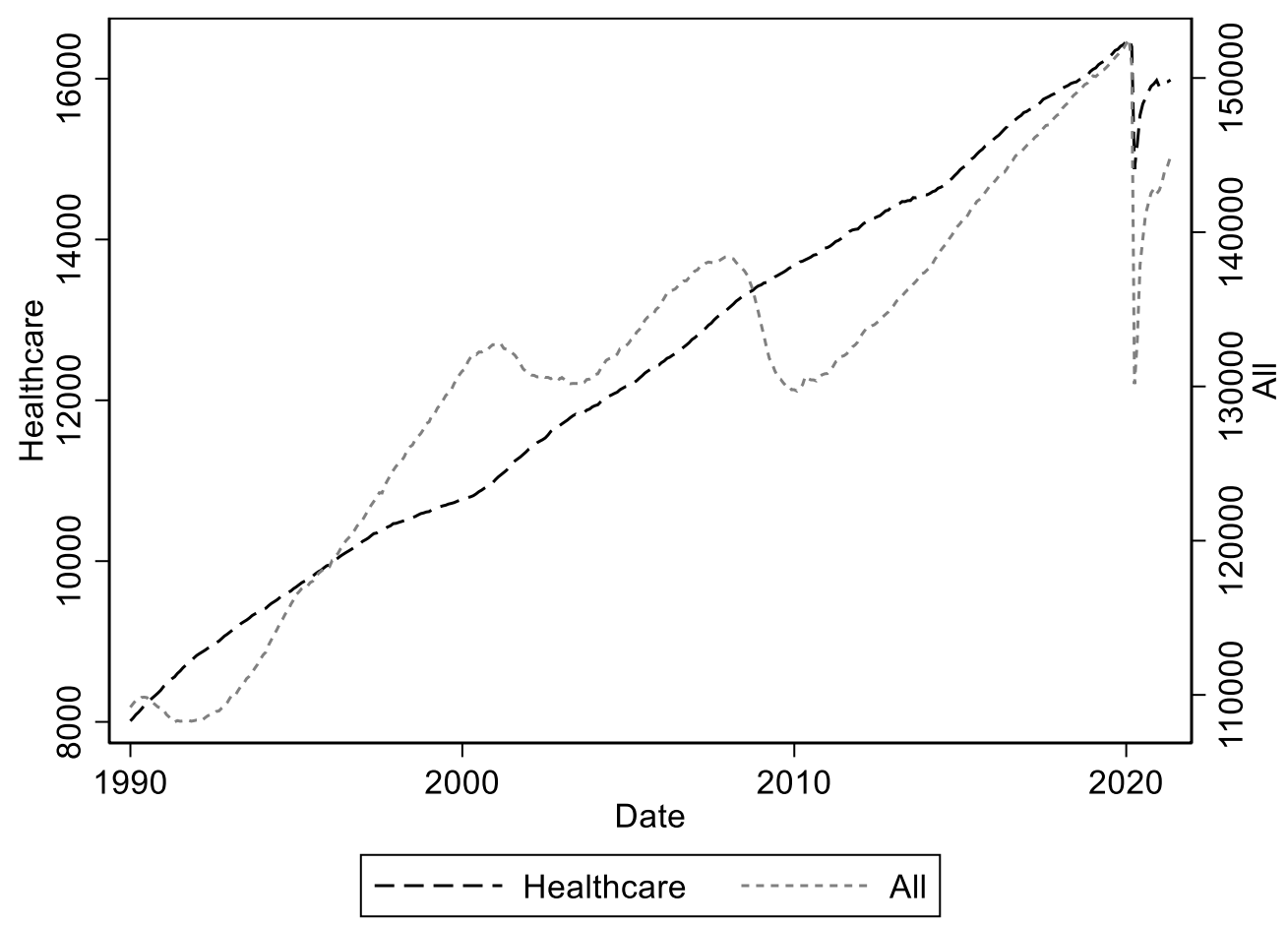

Notes: This figure presents total non-farm employees and healthcare employees (in thousands). U.S. Bureau of Labor Statistics, All Employees, Health Care [CES6562000101], retrieved from FRED, Federal Reserve Bank of St. Louis; https://fred.stlouisfed.org/series/CES6562000101, June 30, 2021. U.S. Bureau of Labor Statistics, All Employees, Total Nonfarm [PAYEMS], retrieved from FRED, Federal Reserve Bank of St. Louis; https://fred.stlouisfed.org/series/PAYEMS, June 30, 2021.

The effects of HICT on tasks and employment will vary across the different types of workers. We compiled data from the U.S. Census of Population (CPS) and the American Community Survey (ACS) from 1980 to 2015 in order to describe the major occupations. Table 1 categorizes 
the healthcare workforce into eight occupational groups. We show some example "suboccupations" within the broader groups to clarify the classification, as well as their employment, education, and wages. Looking at 2015, the largest group is healthcare assistants, who accounted for around a quarter of the healthcare workforce. Nurses are the second largest group (17\%) followed by clerical workers with 13\%. Physicians and healthcare managers as well as professionals associated with medicine (PAM) were smaller groups accounting for 5.8\%, 7.7\%, and $5.4 \%$, respectively.

\section{Table 1: Some Characteristics of the Healthcare Workforce}

\begin{tabular}{|c|c|c|c|c|c|c|c|}
\hline $\begin{array}{l}\text { Broad } \\
\text { Occupation }\end{array}$ & $\begin{array}{l}\text { Example of sub- } \\
\text { occupations (2015 } \\
\text { definitions) }\end{array}$ & $\begin{array}{l}\text { Share of } \\
\text { occupa- } \\
\text { tion with } \\
\text { college } \\
\text { or more, } \\
1980\end{array}$ & $\begin{array}{l}\text { Employ- } \\
\text { ment } \\
\text { share in } \\
\text { healthcare } \\
\text { workforce, } \\
1980\end{array}$ & $\begin{array}{l}\text { Median } \\
\text { hourly } \\
\text { real wage, } \\
1980\end{array}$ & $\begin{array}{l}\text { Share of } \\
\text { occupa- } \\
\text { tion with } \\
\text { college or } \\
\text { more, } 2015\end{array}$ & $\begin{array}{l}\text { Employ- } \\
\text { ment } \\
\text { share in } \\
\text { healthcare } \\
\text { workforce, } \\
2015\end{array}$ & $\begin{array}{l}\text { Median } \\
\text { hourly } \\
\text { real wage, } \\
2015\end{array}$ \\
\hline Physicians & Physician Surgeons & $96.4 \%$ & $7.2 \%$ & $\$ 27.65$ & $99.8 \%$ & $5.8 \%$ & $\$ 68.77$ \\
\hline Nurses & $\begin{array}{l}\text { Registered Nurses } \\
\text { Nurse Anesthetists }\end{array}$ & $32.5 \%$ & $15.5 \%$ & $\$ 19.08$ & $61.5 \%$ & $17.1 \%$ & $\$ 31.16$ \\
\hline PAM & $\begin{array}{l}\text { Chiropractors } \\
\text { Dieticians }\end{array}$ & $59.1 \%$ & $3.8 \%$ & $\$ 18.50$ & $82.6 \%$ & $5.4 \%$ & $\$ 31.77$ \\
\hline $\begin{array}{l}\text { Healthcare } \\
\text { assistants }\end{array}$ & $\begin{array}{l}\text { Dental Hygienists } \\
\text { Licensed Vocational } \\
\text { Nurses }\end{array}$ & $5.2 \%$ & $27.7 \%$ & $\$ 11.06$ & $12.1 \%$ & $23.6 \%$ & $\$ 14.79$ \\
\hline $\begin{array}{l}\text { Healthcare } \\
\text { technicians }\end{array}$ & $\begin{array}{l}\text { Diagnostic-Related } \\
\text { Technologists } \\
\text { Medical Records } \\
\text { Technicians }\end{array}$ & $28.4 \%$ & $6.5 \%$ & $\$ 15.87$ & $33.2 \%$ & $8.0 \%$ & $\$ 20.58$ \\
\hline $\begin{array}{l}\text { Clerical } \\
\text { workers }\end{array}$ & $\begin{array}{l}\text { Bill and Account } \\
\text { Collectors } \\
\text { Customer Service } \\
\text { Representatives }\end{array}$ & $7.6 \%$ & $16.2 \%$ & $\$ 12.00$ & $18.1 \%$ & $12.8 \%$ & $\$ 15.06$ \\
\hline Managers & $\begin{array}{l}\text { General and } \\
\text { Operations } \\
\text { Managers } \\
\text { Medical and Health } \\
\text { Service Managers }\end{array}$ & $38.5 \%$ & $5.1 \%$ & $\$ 19.55$ & $57.7 \%$ & $7.7 \%$ & $\$ 28.66$ \\
\hline Other & $\begin{array}{l}\text { Other Teachers and } \\
\text { Instructors } \\
\text { Transportation } \\
\text { Security Screeners }\end{array}$ & $16.1 \%$ & $18.2 \%$ & $\$ 13.05$ & $30.9 \%$ & $19.6 \%$ & $\$ 15.92$ \\
\hline
\end{tabular}

Notes: Data constructed from U.S. Census of Population data for 1980 and "2015" (2014, 2015, and 2016 pooled), sourced from IPUMS. Healthcare workers are those employed in hospitals, ambulatory healthcare facilities and nursing/residential care facilities. The chain-weighted (implicit) price deflator for personal consumption expenditures deflates real wages to 2015 dollars.

This employment distribution across healthcare occupations is fairly stable over time. For example, the nurse fraction was $15.5 \%$ in 1980 compared to $17.1 \%$ in 2015 . However, there are some changes. Clerical workers have fallen from $16 \%$ to $13 \%$, which is similar to the hollowing 
out of jobs involving routine tasks that we have seen elsewhere in the economy (Acemoglu and Autor 2011). The fastest growing healthcare industry is ambulatory healthcare facilities which is consistent with the global shift toward delivering healthcare through the primary sector rather than through inpatient care.

The CPS/ACS samples are too small to look at changes in very detailed healthcare occupations before and after the HITECH Act, so we turn to the Occupational Employment Statistics from the Bureau of Labor Statistics, which has consistent, detailed breakdowns since 2000. Figure 2 shows the evolution of employment (top panel) and wages (bottom panel) relative to employment and wages in the US as a whole for three groups: nurses, Information Technicians, and medical transcriptionists. For example, in Figure 2 we see in 2018 nurses comprise about $2.7 \%$ of all US workers and have wages that are $40 \%$ higher than the average worker.

In terms of trends, unsurprisingly Information Technicians in the health sector have experienced employment growth (as a share of the healthcare workforce), as well as wage growth.

Meanwhile, Medical Transcriptionists appear to have been displaced with both employment share and wages falling. As a comparison, the large category of nurses experienced wage growth until 2005, when the Information Technicians continued to experience growing wages. To the extent that these trends were driven by HICT, it is consistent with the plausible idea that HICT technicians are a complement to IT, medical transcriptionists a substitute and nurses broadly neutral so far. Looking at the wage ranking in 1980, nurses are the best paid, technicians the worst paid and transcriptionists in the middle. This is consistent with broader concerns that IT innovation displaces workers in the middle of the skill distribution, a topic we describe more fully below. 
Figure 2: Relative Employment and Wages of Nurses, Health Information Technicians and Medical Transcriptionists

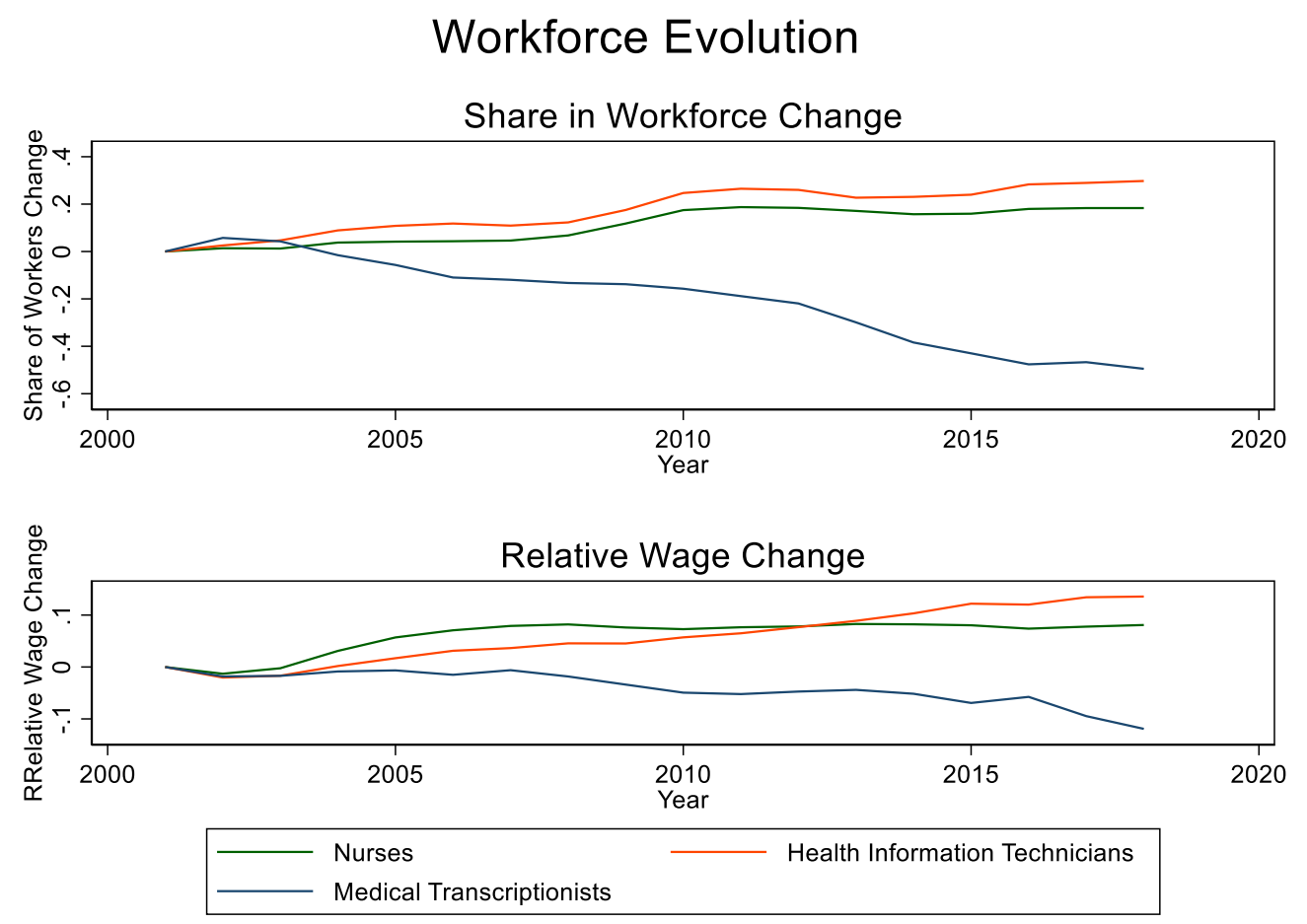

Notes: This figure presents the evolution of nurses, medical transcriptionists and health Information Technicians change in share in the total workforce and the change in their average wage relative to the average in the population. Data is based on Occupational Employment Statistics data provided by the Bureau of Labor Statistics. https://www.bls.gov/oes/tables.htm

\section{Studies of Impact of ICT on Healthcare Workforce}

There have been relatively few studies on the effect of HITC on the healthcare workforce, with most publications describing qualitative concerns rather than providing quantitative support (e.g. Masys (2002); Zeng (2016); McFarlane et al. (2019)).

There have been some microstudies analyzing the effects of HITC implementation on workers and staffing decisions. Bharghava and Mishra (2014) point out that the effect of HITC is not the same for all physicians. They explain that the ratio of information entered versus information used might explain whether or not a physician benefits from information technology. They then exploit the different timing of HITC implementation at 12 clinics involving 87 physicians across 
a wide range of productivity measures to show that family doctors and pediatricians, who must enter a lot of information to the system, perform worse with HITC. Meanwhile internists, who use a lot of information, benefited from the HITC implementation. For example, they show that internal medicine doctors increase their work relative value units (wRVUs) by 1\%, while pediatricians and family doctors reduce their wRVUs by $2 \%$ and $5 \%$, respectively, after the implementation phase. The point that effects will vary by the type of worker-even within classifications like physicians - is one that we believe will be particularly salient as we track these effects going forward.

In the related setting of nursing homes, Lu et al. (2018) employ an IV strategy based on the rate of adoption in nearby hospitals to assess the effect of adopting CPOE on staffing decisions (which assumes there are not unobserved spatially correlated shocks to adoption). They argue that most facilities are at capacity and that they achieve higher revenue by attracting higherpaying customers through quality (vertical) differentiation. They develop a model with technology adoption and vertical differentiation that predicts that HITC will affect nurse demand differently for high-quality vs lower-quality institutions, with IT displacing nurses in the higherquality segment while the opposite is the case for the lower-quality segment. That is, the substitution effect between IT and workers among the more financially successful nursing homes dominates, while the complementarity channel dominates the decision of firms that had more room for improvement. Their findings suggest that lower-quality nursing homes increase staff $7.6 \%$, while higher-quality nursing homes decrease it by $5.8 \%$, following IT implementation. Meanwhile, Hitt and Tambe (2016), described above, find little effect of HITC adoption on labor demand.

The event studies by Agha (2014) described above, examining EHR adoption across hospitals between 1998 and 2004, also considers the impact on employment. The estimates suggest that adoption leads to just over $1 \%$ increases in nurse employment and total employment, but this effect is statistically insignificant.

Some studies look at the impact of HITC on training, including the availability of online courses, which potentially lowers the cost of education and allows for personalized programs. While this is a general trend in all fields, with Global Markets Insights forecasting a growth from $\$ 250$ 
billion in 2020 to over $\$ 1$ trillion by $2027^{13}$, healthcare is especially sensitive as lower quality in education could lead to deadly mistakes. Car et al. (2019) conducted a systematic review of randomized controlled trials (RCTs) on the effectiveness of digital versus traditional learning in this sector. Based on a pooled-analysis of nine RCTs involving 890 healthcare professionals, they find no difference in the gain of knowledge after digital education when compared to traditional strategies.

\section{Summary}

Micro-evidence on the effect of HICT on the workforce is scarce, and in these few studies it is not clear whether adoption is driving workforce changes or whether other characteristics might be driving both. Overall, the summary measures suggest that there are no negative effects on jobs or wages, but some differential impacts on specific groups. This is an area where much more research is needed.

\section{Lessons from other sectors}

There is a vast literature on the impact of ICT on economic outcomes outside of healthcare, and this in turn is a subset of the vast field of the impact of technological change on the economy. A broad motivation in macroeconomics has been the slowdown in productivity growth since the mid-1970s. This is worrisome because, in the long run, productivity growth is the determinant of real wage growth.

The original "Solow Paradox" was that this productivity slowdown coincided with the ICT revolution. Many explanations have been put forward for the paradox, such as mis-measurement and the greater difficulty of innovating as ideas become harder to find (Bloom et al, 2020). However, one leading hypothesis is that it takes a long time between the invention of a major new general-purpose technology (like the computer) and how it feeds through to greater productivity (David, 1990). This was the case for the invention of electricity in the 19th century - it took decades before organizational and social changes were made to make effective use of electricity in industry (e.g., the 24-hour-a-day multi-shift Fordist assembly-line factory).

\footnotetext{
${ }^{13} \mathrm{https} / / /$ www.gminsights.com/industry-analysis/elearning-market-size
} 
With ICT, many complementary investments in workplace organization and management also need to be made to make best use of the new opportunities. In addition, by extension, the most recent waves of radical technologies such as artificial intelligence may take some time before they show up in productivity improvements (Brynjolfsson et al. 2021).

Microeconomic evidence is more compelling than evidence based on macroeconomic data. Much of this is summarized in Draca et al (2007). In short, the studies of firms suggest:

i) A positive and significant association between organizational productivity and the use of ICT.

ii) Although this correlation is on average quite large, it is extremely heterogeneous between studies. In addition, even within studies, the effects are generally quite variable across different firms.

iii) When researchers can look at data over many years, it is clear that the positive effects do not take place immediately, but typically are only revealed after several years.

These findings are consistent with our summary of the healthcare literature and suggest that something broader might be at play than factors specific to healthcare.

The findings lend credence to the "organizational complementarity" story. Firms take time to learn the most effective way to use this technology, and there is much ex-ante uncertainty about the optimal way to implement it, which is why the returns are so variable and slow to happen. Many other types of investment must be made, not least of which is changing the structure of organizations, such as changing the power structure within firms.

Some papers have also used more direct tests of the organizational complementarity explanation by collecting information on the inner workings of firms - for example, their degree of workplace decentralization, HR management practices, and use of teams. ${ }^{14}$ These have all found

14 For example, Bresnahan et al. (2002) for the United States; Caroli and Van Reenen (2001) for the United Kingdom and France; and Bloom et al. (2012) for seven OECD countries. 
important roles for strong complementarities between ICT and organization change that help explain the variety of impacts of ICT on productivity. $\frac{15}{5}$

The literature on the effects of technology on the labor market is also vast, and a focus has been on the impact of ICT on the demand for different types of skills. The broad picture here is that, on average, ICT has increased the demand for the highly skilled - those with a college degree or higher. Hence, as Jan Tinbergen argued, wage inequality can be seen as a race between technologies that increase skill demand pushing inequality up versus the supply of education that will pull inequality down. Autor et al. (2020) show that the slowdown in years of schooling for cohorts entering the labor market since the late 1970s has been a major cause of the rise in the premium to having more education. More recent work suggests that ICT has a more nuanced effect with computers replacing "routine work". For example, tasks traditionally undertaken by low-skilled manual workers on car assembly lines have been largely automated away by robots. However, routine tasks by middle-educated workers doing clerical work were also automated away (e.g., automated teller machines), whereas low-skilled workers doing non-routine work like cleaning have been less affected by ICT. Hence, ICT may have the largest negative impact on middle-skilled workers and lead to polarization of the workforce. We have shown that this might be the case in healthcare and should be an area of future work.

Our sense from the literature is that ICT has two central tendencies: to raise productivity and to increase the demand for more skilled workers. However, the impact is highly variable and mediated by specific features of the environment into which the technology is placed. In particular, the finding that the impact is contingent on organization and management is consistent with our review of healthcare studies.

\section{Conclusions}

We have surveyed the evidence of the impact of HICT on clinical quality, productivity, and on the healthcare workforce. The literature points in a broadly optimistic direction in that the more recent cohort of studies suggests a positive effect on patient outcomes, but a more modest impact

15 For a review of the case study evidence, see Kochan et al. (2020). Examples include Batt (1999), CutcherGershenfeld (1991), Cutcher-Gershenfeld et al. (2007), or MacDuffie (1995). 
on productivity. Like the broader ICT literature, this positive mean impact conceals a lot of heterogeneity underneath and long lags between adoption and outcomes, consistent with learning. Costs tend to rise, however, especially in the early adoption phase. The evidence on workforce outcomes is very slim, but what there is suggests little average effect with a hint of the heterogeneous effects by skill.

An important caveat to all these conclusions is that there are few well-designed studies to get at the causal impact of HICT. Better identification using modern techniques of exploiting policy variation, natural experiments and Randomized Control Trials should be one focus of the field. Another is to look more systematically at the role of the workforce. The relatively recent and enormous growth in the adoption of HICT provides a valuable opportunity to isolate the exogenous sources of variation to estimate these effects to guide policy and improve health. 


\section{References}

Acemoglu, D. and Autor, D., 2011. Skills, tasks and technologies: Implications for employment and earnings. In Handbook of Labor Economics (Vol. 4, pp. 1043-1171). Elsevier.

Ackerberg, D.A., Caves, K. and Frazer, G., 2015. Identification properties of recent production function estimators. Econometrica, 83(6), pp.2411-2451.

Adler-Milstein, J. and Jha, A.K., 2014. No evidence found that hospitals are using new electronic health records to increase Medicare reimbursements. Health Affairs, 33(7), pp.1271-1277.

Adler-Milstein, J. and Pfeifer, E., 2017. Information blocking: is it occurring and what policy strategies can address it? The Milbank Quarterly, 95(1), pp.117-135.

Agha, L., 2014. The effects of health information technology on the costs and quality of medical care. Journal of health economics, 34, pp.19-30.

Agha, L., Ericson, K.M. and Zhao, X., 2020. The Impact of Organizational Boundaries on Healthcare Coordination and Utilization (No. w28179). National Bureau of Economic Research.

Akbik, F., Hirsch, J.A., Chandra, R.V., Frei, D., Patel, A.B., Rabinov, J.D., Rost, N., Schwamm, L.H. and Leslie-Mazwi, T.M., 2017. Telestroke - the promise and the challenge. Part one: growth and current practice. Journal of Neurointerventional surgery, 9(4), pp.357-360.

Altmann, S., Milsom, L., Zillessen, H., Blasone, R., Gerdon, F., Bach, R., Kreuter, F., Nosenzo, D., Toussaert, S. and Abeler, J., 2020. Acceptability of app-based contact tracing for COVID-19: Cross-country survey study. JMIR mHealth and uHealth, 8(8), p.e19857.

Ancker, J.S., Edwards, A., Nosal, S., Hauser, D., Mauer, E. and Kaushal, R., 2017. Effects of workload, work complexity, and repeated alerts on alert fatigue in a clinical decision support system. BMC medical informatics and decision making, 17(1), pp.1-9.

Anderson, G.F., Reinhardt, U.E., Hussey, P.S. and Petrosyan, V., 2003. It's the prices, stupid: why the United States is so different from other countries. Health Affairs, 22(3), pp.89-105.

Arellano, M. and Bond, S., 1991. Some tests of specification for panel data: Monte Carlo evidence and an application to employment equations. The review of economic studies, 58(2), pp.277-297.

Aron, R., Dutta, S., Janakiraman, R. and Pathak, P.A., 2011. The impact of automation of systems on medical errors: evidence from field research. Information systems research, 22(3), pp.429-446.

Atasoy, H., Greenwood, B.N. and McCullough, J.S., 2019. The digitization of patient care: a review of the effects of electronic health records on health care quality and utilization. Annual review of public health, 40, pp.487-500.

Autor, D., Dorn, D., Katz, L.F., Patterson, C. and Van Reenen, J., 2020. The fall of the labor share and the rise of superstar firms. The Quarterly Journal of Economics, 135(2), pp.645-709. 
Autor, D., Goldin, C. and Katz, L., 2020. The Race between Education and Technology Revisited. American Economic Review, forthcoming.

Baratloo, A., Rahimpour, L., Abushouk, A.I., Safari, S., Lee, C.W. and Abdalvand, A., 2018. Effects of Telestroke on thrombolysis times and outcomes: a meta-analysis. Prehospital Emergency Care, 22(4), pp.472-484.

Bates, D.W. and Gawande, A.A., 2003. Improving safety with information technology. New England journal of medicine, 348(25), pp.2526-2534.

Batt, R., 1999. Work organization, technology, and performance in customer service and sales. Ilr Review, 52(4), pp.539-564.

Bhargava, H.K. and Mishra, A.N., 2014. Electronic medical records and physician productivity: Evidence from panel data analysis. Management Science, 60(10), pp.2543-2562.

Bloom, N. and Van Reenen, J., 2007. Measuring and explaining management practices across firms and countries. The quarterly journal of Economics, 122(4), pp.1351-1408.

Bloom, N., Jones, C.I., Van Reenen, J. and Webb, M., 2020. Are ideas getting harder to find? American Economic Review, 110(4), pp.1104-44.

Bloom, N., Lemos, R., Sadun, R. and Van Reenen, J., 2020. Healthy business? Managerial education and management in health care. Review of Economics and Statistics, 102(3), pp.506517.

Bloom, N., Propper, C., Seiler, S. and Van Reenen, J., 2012. Americans do IT better: US multinationals and the productivity miracle. American Economic Review, 102(1), pp.167-201.

Bloom, N., Lemos, R., Sadun, R. and Van Reenen, J., "The Impact of Competition on Management Quality: Evidence from Public hospitals" Review of Economic Studies (2015) 82: 457-489

Bohmer, R.M. and Ferlins, E.M., 2006. Virginia mason medical center. Boston: Harvard Business School.

Bresnahan, T.F., Brynjolfsson, E. and Hitt, L.M., 2002. Information technology, workplace organization, and the demand for skilled labor: Firm-level evidence. The quarterly journal of economics, 117(1), pp.339-376.

Brynjolfsson, E. and Hitt, L.M., 2000. Beyond computation: Information technology, organizational transformation and business performance. Journal of Economic perspectives, 14(4), pp.23-48.

Brynjolfsson, E., Rock, D. and Syverson, C., 2021. The productivity J-curve: How intangibles complement general purpose technologies. American Economic Journal:

Macroeconomics, 13(1), pp.333-72. 
Buntin, M.B., Burke, M.F., Hoaglin, M.C. and Blumenthal, D., 2011. The benefits of health information technology: a review of the recent literature shows predominantly positive results. Health affairs, 30(3), pp.464-471.

Car, L.T., Kyaw, B.M., Dunleavy, G., Smart, N.A., Semwal, M., Rotgans, J.I., Low-Beer, N. and Campbell, J., 2019. Digital problem-based learning in health professions: systematic review and meta-analysis by the digital health education collaboration. Journal of medical Internet research.

Caroli, E. and Van Reenen, J., 2001. Skill-biased organizational change? Evidence from a panel of British and French establishments. The Quarterly Journal of Economics, 116(4), pp.14491492.

Case, A. and Deaton, A., 2020. Deaths of Despair and the Future of Capitalism. Princeton University Press.

Cebul, R.D., Rebitzer, J.B., Taylor, L.J. and Votruba, M.E., 2008. Organizational fragmentation and care quality in the US healthcare system. Journal of Economic Perspectives, 22(4), pp.93113.

Chan, D., Card, D. and Taylor, L., 2020. Is There a VA Advantage? Evidence from Dually Eligible Veterans. Stanford University mimeo.

Chandra, A., Finkelstein, A., Sacarny, A. and Syverson, C., 2016. Health care exceptionalism? Performance and allocation in the US health care sector. American Economic Review, 106(8), pp.2110-44.

Chaudhry, B., Wang, J., Wu, S., Maglione, M., Mojica, W., Roth, E., Morton, S.C. and Shekelle, P.G., 2006. Systematic review: impact of health information technology on quality, efficiency, and costs of medical care. Annals of internal medicine, 144(10), pp.742-752.

Cohn, K.H., 2009. Changing physician behavior through involvement and collaboration. Journal of healthcare management, 54(2), p.80.

Cooper, Z., Craig, S.V., Gaynor, M. and Van Reenen, J., 2019. The price ain't right? Hospital prices and health spending on the privately insured. The quarterly journal of economics, 134(1), pp.51-107.

Cutcher-Gershenfeld, J., 1991. The impact on economic performance of a transformation in workplace relations. ILR Review, 44(2), pp.241-260.

Cutcher-Gershenfeld, J., Kochan, T., Ferguson, J.P. and Barrett, B., 2007. Collective bargaining in the twenty-first century: A negotiations institution at risk. Negotiation Journal, 23(3), pp.249265.

Cutler, D.M., 2011. Where are the health care entrepreneurs? The failure of organizational innovation in health care. Innovation Policy and the Economy, 11(1), pp.1-28.

David, P.A., 1990. The dynamo and the computer: an historical perspective on the modern productivity paradox. The American Economic Review, 80(2), pp.355-361. 
Doyle Jr, J.J., Graves, J.A., Gruber, J. and Kleiner, S.A., 2015. Measuring returns to hospital care: Evidence from ambulance referral patterns. Journal of Political Economy, 123(1), pp.170214.

Doyle, J., Abraham, S., Feeney, L., Reimer, S. and Finkelstein, A., 2019. Clinical decision support for high-cost imaging: a randomized clinical trial. PloS one, 14(3), p.e0213373.

Draca, M., Sadun, R. and Van Reenen, J., 2007. Productivity and ICTs: A review of the evidence. The Oxford handbook of information and communication technologies.

Dranove, D., Forman, C., Goldfarb, A. and Greenstein, S., 2014. The trillion dollar conundrum: Complementarities and health information technology. American Economic Journal: Economic Policy, 6(4), pp.239-70.

Ganju, K.K., Atasoy, H., McCullough, J. and Greenwood, B., 2020. The role of decision support systems in attenuating racial biases in healthcare delivery. Management Science, 66(11), pp.5171-5181.

Ganju, K.K., Atasoy, H. and Pavlou, P.A., 2021. Do Electronic Health Record Systems Increase Medicare Reimbursements? The Moderating Effect of the Recovery Audit Program. Management Science.

Gamache, R., Kharrazi, H. and Weiner, J.P., 2018. Public and population health informatics: the bridging of big data to benefit communities. Yearbook of medical informatics, 27(01), pp.199206.

Gnanlet, A., Choi, M. and Davoudpour, S., 2019. Impediments to the Implementation of Healthcare Information Technology: A Systematic Literature Review. J of Supply Chain and Operations Man, 17(1), p.136.

Gold, M. and McLaughlin, C., 2016. Assessing HITECH implementation and lessons: 5 years later. The Milbank Quarterly, 94(3), pp.654-687.

Goldzweig, C.L., Towfigh, A., Maglione, M. and Shekelle, P.G., 2009. Costs and Benefits of Health Information Technology: New Trends from the Literature: Since 2005, patient-focused applications have proliferated, but data on their costs and benefits remain sparse. Health affairs, 28(Supp12), pp.w282-w293.

Hall, R.E. and Jones, C.I., 2007. The value of life and the rise in health spending. The Quarterly Journal of Economics, 122(1), pp.39-72.

Hall, R.E., 2005. Employment efficiency and sticky wages: Evidence from flows in the labor market. Review of Economics and statistics, 87(3), pp.397-407.

Hardiker, N.R., Dowding, D., Dykes, P.C. and Sermeus, W., 2019. Reinterpreting the nursing record for an electronic context. International journal of medical informatics, 127, pp.120-126. 
Harrington, L., Kennerly, D. and Johnson, C., 2011. Safety issues related to the electronic medical record (EMR): synthesis of the literature from the last decade, 2000-2009. Journal of Healthcare Management, 56(1), pp.31-44.

Hillestad, R., Bigelow, J., Bower, A., Girosi, F., Meili, R., Scoville, R. and Taylor, R., 2005. Can electronic medical record systems transform health care? Potential health benefits, savings, and costs. Health affairs, 24(5), pp.1103-1117.

Hitt, L.M. and Tambe, P., 2016. Health care information technology, work organization, and nursing home performance. Industrial and Labor Relations Review, 69(4), pp.834-859.

Jha, A.K., DesRoches, C.M., Kralovec, P.D. and Joshi, M.S., 2010. A progress report on electronic health records in US hospitals. Health affairs, 29(10), pp.1951-1957.

Kellermann, A.L. and Jones, S.S., 2013. What it will take to achieve the as-yet-unfulfilled promises of health information technology. Health affairs, 32(1), pp.63-68.

Kochan, T.A., 2020. Worker Voice, Representation, and Implications for Public Policies. Research Brief, MIT Task Force on Work of the Future.

Kruse, C.S. and Beane, A., 2018. Health information technology continues to show positive effect on medical outcomes: systematic review. Journal of medical Internet research, 20(2), p.e8793.

Kuhn, K.U. and Van Reenen, J., 2008. Interoperability and market foreclosure in the European Microsoft case.

Lee, J., McCullough, J.S. and Town, R.J., 2013. The impact of health information technology on hospital productivity. The RAND Journal of Economics, 44(3), pp.545-568.

Lin, S.C., Jha, A.K. and Adler-Milstein, J., 2018. Electronic health records associated with lower hospital mortality after systems have time to mature. Health affairs, 37(7), pp.1128-1135.

Litwin, A.S., 2011. Technological change at work: The impact of employee involvement on the effectiveness of health information technology. ILR Review, 64(5), pp.863-888.

Long, L.A., Pariyo, G. and Kallander, K., 2018. Digital technologies for health workforce development in low-and middle-income countries: a scoping review. Global Health: Science and Practice, 6(Supplement 1), pp.S41-S48.

Lu, S.F., Rui, H. and Seidmann, A., 2018. Does technology substitute for nurses? Staffing decisions in nursing homes. Management Science, 64(4), pp.1842-1859.

MacDuffie, J.P., 1995. Human resource bundles and manufacturing performance: Organizational logic and flexible production systems in the world auto industry. ILR Review, 48(2), pp.197-221.

Mantzana, V., Themistocleous, M., Irani, Z. and Morabito, V., 2007. Identifying healthcare actors involved in the adoption of information systems. European Journal of Information Systems, 16(1), pp.91-102. 
Masys, D.R., 2002. Effects of current and future information technologies on the health care workforce. Health affairs, 21(5), pp.33-41.

McCullough, J., Ganju, K.K. and Ellimoottil, C., 2021. Does Telemedicine Transcend Disparities or Create a Digital Divide? Evidence from the COVID-19 Pandemic. Evidence from the COVID-19 Pandemic (April 26, 2021).

McCullough, J.S., Casey, M., Moscovice, I. and Prasad, S., 2010. The effect of health information technology on quality in US hospitals. Health affairs, 29(4), pp.647-654.

McCullough, J.S., Parente, S.T. and Town, R., 2016. Health information technology and patient outcomes: the role of information and labor coordination. The RAND Journal of Economics, 47(1), pp.207-236.

McFarlane, T.D., Dixon, B.E., Grannis, S.J. and Gibson, P.J., 2019. Research Full Report: Public Health Informatics in Local and State Health Agencies: An Update from the Public Health Workforce Interests and Needs Survey. Journal of Public Health Management and Practice, 25(2 Suppl), p.S67.

McKenna, R.M., Dwyer, D. and Rizzo, J.A., 2018. Is HIT a hit? The impact of health information technology on inpatient hospital outcomes. Applied Economics, 50(27), pp.30163028.

Menachemi, N., Rahurkar, S., Harle, C.A. and Vest, J.R., 2018. The benefits of health information exchange: an updated systematic review. Journal of the American Medical Informatics Association, 25(9), pp.1259-1265.

Miller, A.R. and Tucker, C., 2009. Privacy protection and technology diffusion: The case of electronic medical records. Management science, 55(7), pp.1077-1093.

Miller, A.R. and Tucker, C.E., 2011. Can health care information technology save babies? Journal of Political Economy, 119(2), pp.289-324.

Obermeyer, Z., Powers, B., Vogeli, C. and Mullainathan, S., 2019. Dissecting racial bias in an algorithm used to manage the health of populations. Science, 366(6464), pp.447-453.

O’Donovan, J., and Bersin, A. (2015). Controlling Ebola through mHealth strategies. The Lancet Global Health, 3(1), e22.

Olley, S. and Pakes, A., 1996. Dynamic behavioral responses in longitudinal data sets:

Productivity in telecommunications equipment industry. University of Pennsylvania, Philadelphia, PA. http://econweb. umd. edu/haltiwan/olley_pakes. pdf.

Papanicolas, I., Woskie, L.R. and Jha, A.K., 2018. Health care spending in the United States and other high-income countries. Jama, 319(10), pp.1024-1039.

Parente, S.T. and McCullough, J.S., 2009. Health information technology and patient safety: evidence from panel data. Health Affairs, 28(2), pp.357-360. 
Raposo, V.L., 2015. Electronic health records: Is it a risk worth taking in healthcare delivery? GMS health technology assessment, 11.

Rumbold, J.M., O'Kane, M., Philip, N. and Pierscionek, B.K., 2020. Big Data and diabetes: the applications of Big Data for diabetes care now and in the future. Diabetic Medicine, 37(2), pp.187-193.

Sahni, N.R., Huckman, R.S., Chigurupati, A. and Cutler, D.M., 2017. The IT transformation health care needs. Harvard Bus Rev, (Nov-Dec 2017), pp.128-138.

Schmit, C., Sunshine, G., Pepin, D., Ramanathan, T., Menon, A., and Penn, M. (2017). Transitioning from paper to digital: State statutory and regulatory frameworks for health information technology. Public Health Reports, 132(5), 585-592.

Schmit, C.D., Wetter, S.A. and Kash, B.A., 2018. Falling short: how state laws can address health information exchange barriers and enablers. Journal of the American Medical Informatics Association, 25(6), pp.635-644.

Swan, P.L., 1973. The international diffusion of an innovation. The Journal of Industrial Economics, pp.61-69.

Tsugawa, Y., Jha, A.K., Newhouse, J.P., Zaslavsky, A.M. and Jena, A.B., 2017. Variation in physician spending and association with patient outcomes. Jama internal medicine, 177(5), pp.675-682.

Zeng, X., 2016. The impacts of electronic health record implementation on the health care workforce. North Carolina medical journal, 77(2), pp.112-114. 


\section{Appendix}

\section{Definition of Electronic health records}

There are many definitions of Electronic health records and we use some in Figure 1. These follow the Office of the National Coordinator (ONC) definitions (see below) and are more stringent definitions than some researchers have used, which explains why the values of HICT penetration are somewhat lower than some other estimates using the same data sources.

Our definitions are based on a combination of various HICT that a hospital could adopt. The Office of the National Coordinator (ONC) defines that a hospital has "Basic EHR without clinician notes" when the main site of the hospital includes a system with capabilities in the following areas: patient demographics, patient problem lists, electronic lists of medications taken by patients, discharge summaries, advanced directives, CPOE for medications, viewing laboratory results, and viewing radiology results. The ONC definitions can be created directly from the AHA-IT supplement that contains a question on each of these capabilities. The ONC uses this to create its "Dashboard" using sampling weights to correct for non-random sample response. We do not have access to the sampling weights, so Figure 1 also contains our own estimates from AHA-IT.

The Healthcare Information and Management Systems Society (HIMSS) survey captures each hospital's HICT applications along with a small description of what they do. In order to implement the definitions, we utilize language processing to classify whether a hospital has adopted basic EHR by looking for key words in the description of each application. We define a hospital as having Basic HER whenever it has applications for physician documentation, electronic medical records and CPOE.

\section{Methodology}

We incorporate relevant papers from diverse searches on PUBMED, dimension app and google scholar, as well as references found within those papers ${ }^{16}$. To achieve this, we started by searching on PUBMED. We searched with keywords: information technology, health and labor. We found several thousand results and reviewed the abstracts from the 100 most recent articles and the 100 best matches according to PUBMED's search algorithm. As a second effort, we searched with

\footnotetext{
${ }^{16}$ PUBMED is a scientific search engine organized by the National Institute of Health. Dimension App is an AI powered search engine for publications, grants, datasets, publications, patents and policy documents.
} 
keywords: "health" AND "information technology" AND "workforce" and filters: "review". This resulted in 34 articles in the last 5 years. Our third effort consisted of searching for economics papers on the "effect of health information technology". As before, we scanned the 100 most recent papers and the 100 most relevant. As a fourth effort, we used the dimension app to filter papers since 2015 and using the following keywords: "health" AND "technology" AND "workforce" resulting in 541 articles. Overall, this effort, including related works discovered from the search-engine results, left us with 975 papers to review.

To narrow down our search, we focused on peer-reviewed journals and empirically oriented projects for every outcome. The exception is that we reviewed all of the articles specifically about the workforce. In total, we read and summarized 65 papers for our literature review. From these papers, 20 are related to IT adoption, implementation and meaningful use, 14 concern the health workforce (although most are speculative), and 32 focus more on productivity outcomes and cost effects. ${ }^{17}$

\section{Spreadsheet of studies}

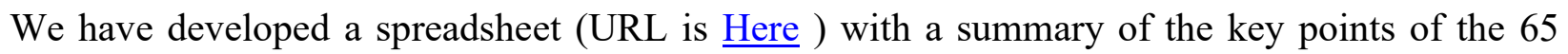
papers we analyzed in detail. Our intention is to provide the reader with the ability to quickly screen the main points discussed in each paper and be able to quickly find additional information on any point that is not discussed in detail in the main text. The spreadsheet includes the paper's title, authors, journal, year of publication and a link to the online publication of the paper. Moreover, we include the following eight sections that describe the main points of each paper: (1) main research question; (2) main results; (3) data; (4) institutional background; (5) type of intervention; (6) empirical strategy; (7) identification evidence; and (8) robustness.

\footnotetext{
${ }^{17}$ One paper is classified as both workforce and productivity effects of IT
} 